\begin{tabular}{ccc}
\hline & International Journal of Engineering \& Technology, 7 (3.5) (2018) 37-39 \\
SPC & International Journal of Engineering \& Technology \\
\hline
\end{tabular}

\title{
Identification of Complex Production Systems with Using Iterative Networks
}

\author{
Korneev A.M., Abdullakh L.S., Sukhanov A.B., Antar, S.D., Al-jonid Kh.M \\ Lipetsk State Technical University \\ *Corresponding author E-mail: d.48@ rambler.ru
}

\begin{abstract}
In the article the technique of identification of complex production systems using iterative networks is considered. The identification process begins with the allocation of functional blocks, which can later be described by automata working with discrete information and changing internal states only at specified times. The basic laws of the functioning of the selected subsystems are simulated. Characteristics of cells formed parameters associated with multi-step manufacturing process. As the semi-finished product passes through the processing stages under consideration, the values of the technological factors being realized are fixed in the system being formed.
\end{abstract}

Keywords: Identification, complex production, iterative networks, the technological factors.

\section{Introduction}

Complex multi-stage production systems can be described in the order of processing steps, each of which includes its own set of production units and operations. Technological operations performed on each unit are combined into separate modules. [1-11]. The identification process begins with the selection of functional blocks that can be subsequently described guns operating with discrete information, and changes the internal state only at predetermined times (cycles). The blocks correspond to the individual stages of the processing of the iterative network represented as cells. Operations reflecting the stages of processing are represented as separate cells with memory. As a result, a linear iterative network is formed, describing the technological process.

In the first stage of the iterative network description formulated the principles of all the machines, ie. E. Define the conditions of their interaction with all the other objects that formed the ins and outs of each machine. An ordered chain of automata forming a system is characterized by the fact that one or several outputs of each previous automaton are connected to the inputs of the next automaton. After the structure of the system is determined and the list of its subsystems is determined, the next stage simulates the basic laws of the functioning of the selected subsystems. A formal description of subsystems is performed. For the management of the cell chain, the functioning algorithms that determine the order of implementation of individual operations and procedures. During the process of the iterative network operation in accordance with the selected internal algorithm, a sequence of necessary control signals is generated, which are transferred to the functional modeling units. In order for the iterative network of a multi-block system to implement an algorithm of its functioning, links are created between the individual blocks, which determine the order of the entire operation of the function blocks during the control process.

\section{Research method}

Complex multi-step industrial systems are characterized by a discrete time and space of the structure. They are characterized by a complex structure of relations between all the inputs, states and outputs. In the proposed iterative network is identification of individual treatment stages with the cells of the network.

In the next stage are formed operating conditions of each machine (cells iterative network), ie. E. Formulated conditions of interaction with any other objects multistage system identified inputs, and outputs the iterative simulated network of cells and common law determining signals from internal and external inputs the network in question. A ordered sequence of cells forming system, characterized by the previous machine communication with followed by a machine.

The simulated networks are iterative. Characteristics of cells formed parameters associated with multi-step manufacturing process. By ongoing technological factors values recorded as it passes by the present step semifinished processing system formed. As a result, signals produced by cells iterative network dependent cell signals developed at earlier stages of the processing implemented process (its iterations).

The one-dimensional bi-directional linear iterative network of a multi-stage production process is shown in figure 1 . 


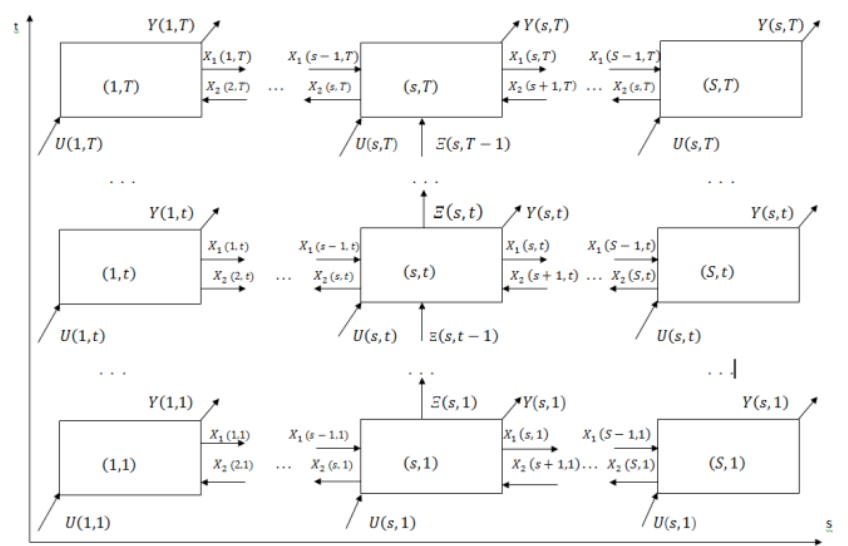

Fig. 1: The one-dimensional bi-directional linear iterative network of a multi-stage production process.

Each cell $(\mathrm{s}, \mathrm{t})$ the network is in a particular state $\Xi(\mathrm{s}, \mathrm{t})$ it is able to receive input signals internally $\mathrm{X}_{1}(\mathrm{~s}-1, \mathrm{t})$ and $\mathrm{X}_{2}(\mathrm{~s}+1, \mathrm{t})$ an external input signals $\mathrm{U}(\mathrm{s}, 1)$ (as a reaction cell) cell generates internal output signals $\quad X_{1}(s, t), X_{2}(s, t)$ and description of the output signalY $(s, t)$.

The number of external input cells corresponds to the number of types of resources being spent on the unit (cell s.

Вектор $U(\mathrm{~s}, \mathrm{t})$ It describes the consumption of resources $\mathrm{Z}(\mathrm{s}, \mathrm{t})$ entering the cell (unit) $s$ the period of time $t$

$\mathrm{u}(\mathrm{s}, \mathrm{t})=\mathrm{z}(\mathrm{s}, \mathrm{t})$

$$
\mathrm{Z}(S, t)=\left\{\begin{array}{c}
z\left(s, 1_{s}, t\right) \\
\cdots \cdots \\
z\left(s, g_{s}, t\right) \\
\cdots \cdots \\
z\left(s, G_{s}, t\right)
\end{array}\right.
$$

Где $g_{s}=1_{s}, \ldots, G_{s}$ - types of resources used in the $\mathrm{S}$-th unit, $\mathrm{G}_{\mathrm{s}}$ - the amount of resources

Internal output signal $X_{1}(s, t)$ it contains information about the volume of production of each type of product $\bar{X}_{1}(s, t)$ values of process factors obtained in the unit

$\mathrm{S}$ in the moment $\mathrm{t}$

$\mathrm{X}_{1}^{* *}(\mathrm{~s}, \mathrm{t})$. Inputs and outputs of the cells of the iterative network multistage manufacturing process are shown in Fig.2.

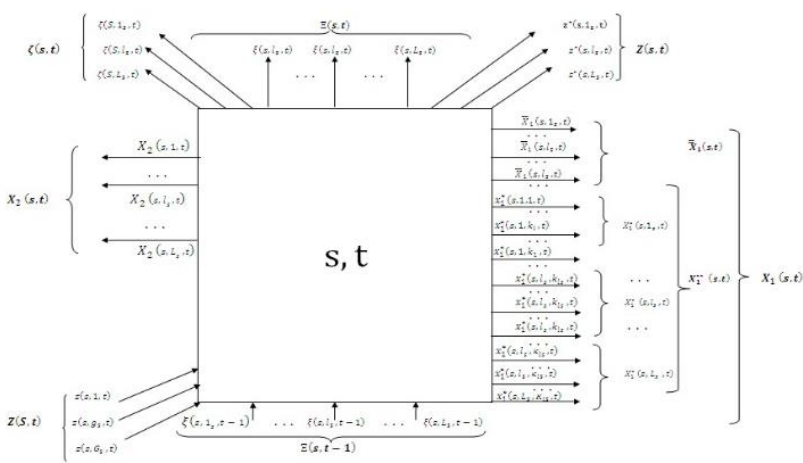

Fig. 2: Inputs and outputs of the cells of the iterative network multistage manufacturing process

$X_{1}(s, t)=\left(X_{1}^{* *}(s, t), \bar{X}_{1}(s, t)\right)$
Vector $X_{1}^{* *}(s, t)$ contains information on the processing technology of production on the unit (cell) s. For each type of product 1 (s) is formed by a set of investigated technological factors $X_{1}^{*}\left(S, l_{s}, t\right)$, implemented in the unit $\mathrm{S}$ at time t. Eventually:

$$
X_{1}^{* *}(s, t)\left\{\begin{array}{c}
x_{1}^{*}\left(s, 1_{s}, t\right) \\
\cdots \\
x_{1}^{*}\left(s, l_{s}, t\right) \\
\cdots \\
x_{1}^{*}\left(s, L_{s}, t\right)
\end{array}\right.
$$

Retentive factors for each type of product

$$
X_{1}^{*}\left(S, l_{s}, t\right)=\left\{\begin{array}{c}
x_{1}^{*}\left(s, l_{s}, 1_{l s}, t\right) \\
\ldots \\
x_{1}^{*}\left(s, \dot{l}_{s}, k_{l s}, t\right) \\
\ldots \\
x_{1}^{*}\left(s, \dot{l}_{s}, K_{l s}, t\right)
\end{array}\right.
$$

Where $k_{l s}=1_{l s}, \ldots, k_{l s}$ - factors, fixed for $l_{s}$ - steel grade, $k_{l s}$ the total number of technological factors.

\section{Results and analysis}

The technique allows to determine the flow of resources for different steel grades and sizes..

In this case, the flow of resources generated matrix on steel grade and standard sizes

$$
X_{1}^{*}\left(s, l_{s}, k_{q l s}, t\right)=\left\{\begin{array}{c}
x_{1}\left(s, l_{s}, 1_{l s}, k_{1 l s}, t\right) \\
\ldots \\
x_{1}\left(s, l_{s}, q_{l s}, k_{q l s} t\right) \\
\ldots \\
x_{1}\left(s, l_{s}, Q_{l s}, k_{q l s}, t\right)
\end{array}\right.
$$

For all sizes. Where $k$ - factor for size $q_{l s}$.

Costs for all sizes

$$
\bar{Z}\left(S, t, g_{l s}\right)=\left\{\begin{array}{c}
z\left(s, l_{s}, 1_{l s}, g_{1 l s}, t\right) \\
\ldots \\
z\left(s, l_{s}, q_{l s}, g_{s}, g_{q l s}, t\right) \\
\ldots \\
z\left(s, l_{s}, Q_{l s}, g_{q l s}, t\right)
\end{array}\right.
$$

Costs for the 1-st size

$$
\overline{\bar{Z}}\left(S, t, q_{l s}\right)=\left\{\begin{array}{c}
z\left(s, l_{s}, q_{l s}, 1_{q l s}, t\right) \\
\ldots \\
z\left(s, l_{s}, g_{q l s}, t\right) \\
\ldots \\
z\left(s, l_{s}, q_{l s}, G_{q l s}, t\right)
\end{array}\right.
$$

$X_{2}(s, t)$ - Costs for the production of products for cell s-1 at time

$X_{2}(s, t)=\left\{\begin{array}{c}X_{2}\left(s, 1_{s}, t\right) \\ \cdots \\ X_{2}\left(s, l_{s}, t\right) \\ \cdots \\ X_{2}\left(s, L_{s}, t\right)\end{array}\right.$

Unfinished production 


$$
\Xi(s, t)=\left\{\begin{array}{c}
\Xi\left(S-1, l_{s-1}, t\right) \\
\cdots \\
\Xi\left(S-1, l_{s-1}, t\right) \\
\cdots \\
\Xi\left(S-1, L_{s-1}, t\right)
\end{array}\right.
$$

\section{Conclusion}

Using iterative linear networks makes it possible to take account of work in progress semi-finished product from one unit to another within a specified time by using cells with memory, taking into account the time variable. With the help of one-dimensional iterative bidirectional networks is carried out to identify multi-step manufacturing processes. Tracking metal dynamics motion processing steps on the analyzed time periods.

\section{References}

[1] Abdullah L.S, Korneev A.M, Smetannikova T.A, (2013), Structural cell-hierarchical identification of complex spatially distributed production systems, Proceedings of the 3rd International Academic Conference. St. Louis, Missouri, USA. C.75-79.

[2] Korneev, A. M, (2009), Methods for the identification of cross-cutting technology production of steel products: monograph / Lipetsk state pedagogical University. - Lipetsk: LGU, p. 286.

[3] Korneev, A. M, (2011), cellular Structural-hierarchical modeling of complex prostranstvenno-distributed systems. - News of higher educational institutions of the Central Chernozem region, No. 1, pp. 62 66.

[4] Kuznetsov, L. A., A. Korneev, M, (1994), Automated system of selecting the optimal technology for the production of steel. - Izvestiya vuzov. Ferrous metallurgy, No. 5, pp. 45-48.

[5] Stratonovich, R. L(1975), Theory of information. - Moscow: Sov. radio, p. 424. Korneev, A. M, (2004), the Use of information criteria connection input and output variables for the selection of optimal technologies - Izvestiya vuzov. Ferrous metallurgy, No. 9, pp. 48 52.

[6] Korneev, A. M, (2008), Criteria communication technologies and properties, taking into account costs and the cost of the finished product. - Control systems and information technology, Vol. 31, No. 1.1, pp.

$160-162$ Russian letters.

[7] M. Shmyrin, I. A. Sedykh, (2010), Identification and Control Algorithms of Functioning for Neighborhood Systems Based on Petri Nets, Automation and Remote Control, Vol. 71, Issue 6, pp. 1265 1274.

[8] S.L. Blyumin, A.M. Shmyrin, O.A. Shmyrina, (2006), Bilinear Neighborhood Systems. Monograph. Lipetsk, Lipetsk State Technical University Publishers, p. 131, (in Russian).

[9] A.L. Genkin, I.V. Nikulin, (2011), The Use of Simulation in the Control Sheet-Rolling Complex, Informacionnye Tehnologii i Vychislitel'nye Sistemy, No. 2, pp. 75-79, (in Russian).

[10] A.M. Korneev, L.S.Abdullakh, T.A. Smetannikova, (2015), CRITERION FOR ASSESSING THE EFFECTIVENESS OF FUNCTIONING OF COMPLEX SYSTEMS BASED ON THE USE THE AMOUNT OF INFORMATION, International Journal of Applied Engineering Research, T. 10, No. 11, pp. 27961-27980.

[11] J.K. Alekseev, A.P. Sukhorukov, (2013), Introduction to the Theory of Catastrophes, Librokom, pp. 176.

[12] Korneev, A.M; Nagi, AM; Vasyukov, AM; Smetannikova, TT ; Antar, SD. Describing Discrete Cell-Hierarchical Systems Using Iterative Networks. International Journal of Advanced Biotechnology and Research. Vol. 8 I 